\title{
Efficacy and tolerability of nanoparticle albumin-bound paclitaxel in combination with carboplatin as a late-phase chemotherapy for recurrent and advanced non-small-cell lung cancer: A multi-center study of the Fukushima lung cancer association group of surgeons
}

\author{
MITSUNORI HIGUCHI ${ }^{1}$, HIRONORI TAKAGI $^{1}$, YUKI OWADA ${ }^{1}$, TAKUYA INOUE ${ }^{1}$, YUZURU WATANABE ${ }^{1}$, \\ TAKUMI YAMAURA ${ }^{1}$, MITSURO FUKUHARA $^{1}$, SATOSHI MUTO $^{1}$, NAOYUKI OKABE $^{1}$, YUKI MATSUMURA ${ }^{1}$, \\ TAKEO HASEGAWA ${ }^{2}$, ATSUSHI YONECHI ${ }^{3}$, JUN OSUGI ${ }^{1}$, MIKA HOSHINO $^{1}$, YUTAKA SHIO ${ }^{4}$, \\ KOICHI FUJIU ${ }^{5}$, RYUZO KANNO ${ }^{6}$, AKIO OHISHI ${ }^{6}$, HIROYUKI SUZUKI ${ }^{1}$ and MITSUKAZU GOTOH $^{1}$ \\ ${ }^{1}$ Department of Chest Surgery, Division of Surgery, Fukushima Medical University School of Medicine, Fukushima 960-1295; \\ ${ }^{2}$ Department of Thoracic Surgery, Shirakawa Kosei General Hospital, Shirakawa, Fukushima 961-0005; \\ ${ }^{3}$ Department of Thoracic Surgery, Takeda General Hospital, Aizuwakamatsu, Fukushima 965-8585; \\ ${ }^{4}$ Department of Surgery, Fukushima Rosai Hospital, Iwaki, Fukushima 973-8403; \\ ${ }^{5}$ Department of Thoracic Surgery, Southern Tohoku General Hospital, Koriyama, Fukushima 963-8563; \\ ${ }^{6}$ Department of Thoracic Surgery, Fukushima Red Cross Hospital, Fukushima 960-8530, Japan
}

Received October 21, 2015; Accepted January 10, 2017

DOI: $10.3892 / 01.2017 .5998$

\begin{abstract}
The present retrospective multi-center study aimed to evaluate the efficacy and feasibility of nanoparticle albumin-bound (nab)-paclitaxel plus carboplatin as a second or late-phase chemotherapy in patients with non-small cell lung cancer (NSCLC). A total of 25 patients with recurrent or advanced NSCLC who had received previous chemotherapy were treated with nab-paclitaxel $\left(70-100 \mathrm{mg} / \mathrm{m}^{2}\right.$,intravenously) on days 1,8 and 15 every 28 days with a carboplatin area under the concentration-time curve of 4-6 on day 1 . The overall response rate, disease control rate, progression-free survival (PFS), overall survival (OS) and toxicities were statistically
\end{abstract}

Correspondence to: Dr Mitsunori Higuchi, Department of Chest Surgery, Division of Surgery, Fukushima Medical University School of Medicine, 1-Hikarigaoka, Fukushima 960-1295, Japan

E-mail: higuchi@fmu.ac.jp

Abbreviations: NSCLC, non-small cell lung cancer; PFS, progression-free survival; OS, overall survival; EGFR, epidermal growth factor receptor; TKIs, tyrosine kinase inhibitors; ALK, anaplastic lymphoma kinase; nab-paclitaxel, nanoparticle albumin-bound paclitaxel; ECOG, Eastern Cooperative Oncology Group; AUC, area under the curve; CR, complete response; PR, partial response; $\mathrm{SD}$, stable disease; $\mathrm{PD}$, progressive disease; ORR, overall response rate; DCR, disease control rate

Key words: nanoparticle albumin-bound paclitaxel, non-small cell lung cancer, overall response rate, disease control rate, adverse events evaluated. Of the 25 patients, there were 9 cases of recurrent disease following surgery, 16 cases of advanced disease, 13 cases of adenocarcinoma, 11 cases of squamous cell carcinoma and 1 case of large cell carcinoma. A total of 13 patients received second-line chemotherapy and 12 received fourth-line or later chemotherapy. One patient exhibited a complete response, 7 had a partial response, 10 exhibited stable disease and 7 had progressive disease. The overall response rate was $32.0 \%$ and the disease control rate was $72.0 \%$. The median PFS and median OS following nab-paclitaxel treatment were 4.0 and 14.0 months, respectively. Frequent treatment-associated adverse events were myelosuppression, peripheral neuropathy, gastrointestinal symptoms and baldness, the majority of which were grade 1-2. Grade 3-4 neutropenia, thrombocytopenia and anemia occurred in $7(28.0 \%), 3(12.0 \%)$ and $2(8.0 \%)$ patients, respectively. No patients experienced grade 3-4 sensory neuropathy and no grade 5 adverse effects were observed. Nab-paclitaxel plus carboplatin as second-phase or later chemotherapy provided a small but significant survival benefit for patients with recurrent or advanced NSCLC, with tolerable adverse effects. To the best of our knowledge, the results of the present study demonstrated for the first time that nab-paclitaxel plus carboplatin is a promising and feasible late-phase chemotherapeutic agent for NSCLC.

\section{Introduction}

Lung cancer is the leading cause of cancer-associated mortality worldwide (1). Advances in the treatment of non-small cell lung cancer (NCSLC) in the past decade include third-generation platinum doublets, epidermal growth factor receptor (EGFR) tyrosine kinase inhibitors (TKIs) in EGFR 
mutation-positive lung cancer, anaplastic lymphoma kinase (ALK) TKIs in ALK rearrangement-positive disease, maintenance systemic therapy and second- or third-line treatment, all of which have improved survival (2-9). Third-generation chemotherapeutic agents, including paclitaxel, docetaxel, gemcitabine, pemetrexed and vinorelbine, in combination with platinum compounds, are the most frequently used treatments for recurrent and advanced NSCLC (10). Among these agents, paclitaxel is particularly problematic with regards to toxicity and solubility (11). Paclitaxel is a hydrophobic compound, and the polyoxyethylated castor oil Kolliphor ${ }^{\circledR}$ EL (Merck KGaA, Darmstadt, Germany) and ethanol are used as vehicles for its parenteral administration; however, this route of administration may lead to an acute hypersensitivity reaction, requiring premedication with antihistamines or corticosteroids (12). Nanoparticle albumin-bound (nab)-paclitaxel is a solvent-free albumin-bound form of paclitaxel. This composition provides a novel approach for increasing the intratumoral concentration of the therapeutic agent via a receptor-mediated transport process, allowing transcytosis across the endothelial cell wall. Albumin transcytosis is then able to deliver the associated paclitaxel to the tumor interstitium $(13,14)$. Nab-paclitaxel is also able to enter the tumor interstitium through leaky junctions in the vascular endothelium (15). A number of previous studies have reported the efficacy of nab-paclitaxel as a first-line chemotherapeutic agent for NSCLC (16-18); however, to date, the efficacy of nab-paclitaxel with carboplatin as a second-phase or later chemotherapy for NSCLC has yet to be established $(19,20)$. In the present study, a retrospective evaluation of the efficacy and feasibility of nab-paclitaxel plus carboplatin as a second-phase or later chemotherapy in patients with recurrent and advanced NSCLC was performed.

\section{Materials and methods}

Study population. The present retrospective study included 25 eligible patients treated at the Division of Chest Surgery of Fukushima Medical University (Fukushima, Japan) and Fukushima Lung Cancer Association Group of Surgeons participating institutions, including the Department of Thoracic Surgery, Shirakawa Kosei General Hospital (Shirakawa, Japan), the Department of Thoracic Surgery, Takeda General Hospital (Aizuwakamatsu, Japan), the Department of Surgery, Fukushima Rosai Hospital (Iwaki, Japan), the Department of Thoracic Surgery, Southern Tohoku General Hospital (Koriyama, Japan) and the Department of Thoracic Surgery, Fukushima Red Cross Hospital (Fukushima, Japan), between July 2013 and January 2015. These patients were histologically or cytologically confirmed as having NSCLC prior to receiving chemotherapy. The inclusion criteria were as follows: Patients with recurrent NSCLC following radical surgery and patients with unresectable stage IIIB/IV NSCLC. The staging was performed according to the 7th Edition Lung Cancer Tumor Node Metastasis Classification and Staging System (21). Histological evaluation was performed according to World Health Organization classification of tumors of the lung, pleura, thymus and heart (22). The present study included 19 male and 6 female patients aged 54-78 years, with a mean age of $66.0 \pm 6.5$ years. In all patients, the presence of measurable lesions was confirmed using computed tomography (CT) scans, and the Eastern Cooperative Oncology Group scores (23) were 0-1. Patient clinicopathological features are summarized in Table I. The protocol was conducted in accordance with the Declaration of Helsinki and Good Clinical Practice guidelines. Written consent was obtained from each patient or their family members at the time of enrollment in the study.

Detection of EGFR mutations and ALK translocation. The cobas EGFR assay (Roche Diagnostics GmbH, Mannheim, Germany) is an allele-specific quantitative polymerase chain reaction system that measures the amplification of DNA to identify 41 mutations in exon $18-21$ of the EGFR gene from $50 \mathrm{ng}$ of DNA derived from human formalin-fixed paraffin-embedded NSCLC tissues. Within each reaction mixture, exon 28 was amplified as an internal control. DNA samples obtained from specimens were amplified using the following site-specific primers: Exon 18 forward, 5'-TGG AGCCTCTTACACCCAGT-3' and reverse, 5'-ACAGCTTGC AAGGACTCTGG-3'; exon 19 forward, 5'-TCTGGATCCCAG AAGGTGAG-3' and reverse, 5'-CAGCTGCCAGACATG AGAAA-3'; exon 20 forward, 5'-CATTCATGCGTCTTCACC TG-3' and reverse, 5'-GTCTTTGTGTTCCCGGACAT-3'; and exon 21 forward, 5'-GATCTGTCCCTCACAGCAGGGTC-3' and reverse, 5'-GGCTTGACCTAAAGCCACCTCC-3'. All results were automatically performed by cobas 4800 software. The analysis of the tumors for ALK gene rearrangement was performed by immunohistochemistry on a Histofine ALK intercalated antibody-enhanced polymer (iAEP) kit (Nichirei Biosience Inc., Tokyo, Japan) using the ALK antibody clone 5A4 (Nichirei Bioscience Inc.) with the iAEP detection kit (Nichirei Bioscience Inc.). These processes were performed as previously described (24).

Nab-paclitaxel treatment plan. A total of 25 patients, who had received previous chemotherapy, were treated with nab-paclitaxel (Abraxane ${ }^{\circledR}$; Taiho Pharmaceutical Co., Ltd., Tokyo, Japan) at a dose of $70-100 \mathrm{mg} / \mathrm{m}^{2}$ administered intravenously on days 1,8 and 15 , with a carboplatin area under the concentration-time curve (AUC) of 4-6 on day 1, every 28 days. Treatment was repeated every 4-6 weeks until disease progression or unacceptable toxicity occurred. If patients experienced hematological toxicities such as grade 3 or 4 neutropenia or thrombocytopenia during treatment, subcutaneous injection of granulocyte colony-stimulating factor was recommended.

Assessment of response rate and adverse events. The response to nab-paclitaxel plus carboplatin was evaluated using the Response Evaluation Criteria in Solid Tumors 1.1 (25). Target lesions were assessed using CT scans, and the observation indicators included complete response (CR), partial response $(\mathrm{PR})$, stable disease (SD) and progressive disease (PD). Furthermore, the overall response rate (ORR) and disease control rate (DCR) were assessed. Patients who completed $>2$ cycles of nab-paclitaxel treatment were evaluated for toxicity. Treatment-associated toxicities were scored according to the National Cancer Institute's Common Terminology Criteria for Adverse Events version 4.0 (26). 
Statistical analysis. The Fisher's exact test was used for the analysis of categorical variables and an unpaired Student's $t$-test was used for the analysis of continuous variables. Survival probabilities were estimated using the Kaplan-Meier method. Statistical analysis was conducted using SPSS version 21.0 (IBM SPSS, Armonk, NY, USA). All tests were two-sided and $\mathrm{P}<0.05$ was considered to indicate a statistically significant difference.

\section{Results}

Patients characteristics. Of the 25 patients, there were 9 cases of recurrent disease following surgery and 16 advanced cases. Of these patients, there were 11 cases of squamous cell carcinoma, 13 cases of adenocarcinoma, and 1 case of large cell carcinoma. EGFR mutation status was positive in $5(20.0 \%)$ patients, and all patients received EGFR-TKIs, including gefitinib or erlotinib, as a component of serial chemotherapy. There were no positive cases of ALK translocation in the present study. All patients had undergone previous chemotherapy, and the regimen of nab-paclitaxel plus carboplatin was administered as a second-line chemotherapy in $13(52.0 \%)$ patients, third-line chemotherapy in $6(24.0 \%)$ patients, fourth-line chemotherapy in $3(12.0 \%)$ patients and fifth-line or later chemotherapy in $3(12.0 \%)$ patients. Individual patients underwent 2-6 cycles (mean, 3.1 cycles) of this regimen. The chemotherapy regimens administered prior to nab-paclitaxel plus carboplatin were primarily S-1 (tegafur/gimeracil/oteracil) plus platinum, pemetrexed plus platinum, gemcitabine plus platinum, EGFR-TKI and docetaxel monotherapy (Table II). Furthermore, later chemotherapy regimens, administered following nab-paclitaxel plus carboplatin, included docetaxel monotherapy, EGFR-TKI, S-1 monotherapy, radiation therapy and best supportive care. The later phase chemotherapy regimens, received following nab-paclitaxel plus carboplatin, are detailed in Table III.

Response to treatment and survival analysis. CR was observed in 1 patient, PR in 7 patients, SD in 10 patients and PD in 7 patients. The mean overall survival (OS) time following first-line chemotherapy was 30.0 months. The ORR and DCR obtained following treatment with nab-paclitaxel with carboplatin were 32.0 and $72.0 \%$, respectively (Table IV). The median progression-free survival (PFS) time and median survival time (MST) following nab-paclitaxel plus carboplatin treatment were 4.0 and 14.0 months, respectively (Fig. 1). Subgroup analysis involved the evaluation of the ORR and DCR according to gender (male vs. female), age ( $<70$ vs. $\geq 70$ years), histology (squamous vs. non-squamous) and chemotherapy phase (second vs. third or later phase; Table IV). In these subgroup analyses, the only parameter that differed significantly was the ORR, which was 16.7 vs. $71.4 \%$ in patients aged $<70$ and $\geq 70$ years, respectively $(\mathrm{P}=0.008)$. However, no significant differences in DCR were identified between these age groups $(\mathrm{P}=0.968)$. In the groups subdivided according to histology (squamous vs. non-squamous), no significant differences were observed in the PFS and OS between the two groups $(\mathrm{P}=0.110$ and $\mathrm{P}=0.245$, respectively; Fig. 2). In the subgroups divided according to age (<70 vs $\geq 70$ years), no significant differences were identified in the
Table I. Patients clinicopathological characteristics.

\begin{tabular}{lc}
\hline Clinical factor & $\begin{array}{c}\text { Number of } \\
\text { patients }(\%)\end{array}$ \\
\hline Gender & $19(76)$ \\
Male & $6(24)$ \\
Female & \\
Age, years & $66.0 \pm 6.5$ \\
Median \pm SD & $18(72)$ \\
$<70$ & $7(28)$ \\
$\geq 70$ & \\
Indications for chemotherapy & $9(36)$ \\
Recurrence following surgery & $16(64)$ \\
Advanced cancer & \\
Recurrent or metastatic sites & $8(32)$ \\
Mediastinal lymph node & $6(24)$ \\
Pleural dissemination & $5(20)$ \\
Adrenal gland & $4(16)$ \\
Brain & $3(12)$ \\
Bone & $2(8)$ \\
Liver & $2(8)$ \\
Other &
\end{tabular}

\section{Histology}

Squamous cell carcinoma $11(44)$

Adenocarcinoma $13(52)$

Large cell carcinoma

EGFR mutation

Positive

Wild type

Unknown

ALK rearrangement

Positive $0(0)$

Negative $6(24)$

Unknown $19(76)$

Phase of nab-paclitaxel chemotherapy

2nd line

3rd line

4th line

5th line

6th line or later

SD, standard deviation; EGFR, epidermal growth factor receptor; ALK, anaplastic lymphoma kinase; nab, nanoparticle albumin-bound.

PFS and OS between the two groups $(\mathrm{P}=0.727$ and $\mathrm{P}=0.270$, respectively; Fig. 3).

Adverse events. The treatment-associated adverse events that occurred most frequently were myelosuppression, sensory neuropathy, gastrointestinal symptoms and baldness, the majority of which were grade 1-2 (Table V), whereas grade 3-4 neutropenia was present in 7 (28.0\%) patients, 
Table II. Treatment prior to the administration of nanoparticle albumin-bound-PTX plus carboplatin therapy.

\begin{tabular}{|c|c|c|c|c|c|}
\hline Regimen & 1st line & 2nd line & 3rd line & 4th line & 5 th line or later \\
\hline S-1+platinum & 8 & 0 & 0 & 0 & 0 \\
\hline $\mathrm{BEV}+\mathrm{PEM}+$ platinum & 7 & 3 & 0 & 0 & 0 \\
\hline PEM+platinum & 4 & 1 & 0 & 0 & 0 \\
\hline PTX+platinum & 2 & 0 & 0 & 0 & 0 \\
\hline GEM+platinum & 1 & 1 & 0 & 0 & 0 \\
\hline EGFR-TKI & 2 & 4 & 1 & 0 & 4 \\
\hline Single DOC & 0 & 4 & 1 & 0 & 0 \\
\hline Others & 1 & 0 & 0 & 2 & 4 \\
\hline
\end{tabular}

S-1, tagafur/gimeracil/oteracil; BEV, bevacizumab; PEM, pemetrexed; PTX, paclitaxel; GEM, gemcitabine; EGFR-TKI, epidermal growth factor receptor-tyrosine kinase inhibitor; DOC, docetaxel.

Table III. Later phase treatments following nab-PTX plus carboplatin therapy.

\begin{tabular}{lccc}
\hline Regimen & $\begin{array}{c}\text { Following } \\
\text { nab-PTX, }\end{array}$ & $\begin{array}{c}\text { Later } \\
\text { phase, } \mathrm{n}\end{array}$ & Total, $\mathrm{n}$ \\
\hline Continuation & 7 & 0 & 7 \\
BSC & 5 & 3 & 8 \\
Single DOC & 4 & 2 & 6 \\
Single S-1 & 3 & 3 & 5 \\
EGFR-TKI & 2 & 1 & 3 \\
RTX & 0 & 2 & 2 \\
Others & 4 & 2 & 6 \\
\hline
\end{tabular}

BSC, best supportive care; DOC, docetaxel; S-1, tegafur/gimeracil/oteracil; EGFR-TKI, epidermal growth factor receptor-tyrosine kinase inhibitor; RTx, radiation therapy; nab-PTX, nanoparticle albumin-bound paclitaxel.

thrombocytopenia in $3(12.0 \%)$ patients and anemia in 2 $(8.0 \%)$ patients. No grade $3-4$ sensory neuropathies were observed. Dose reduction was required in $28.0 \%$ of patients due to toxicity, but no grade 5 adverse effects were observed. In addition, $5(20.0 \%)$ patients did not experience any adverse events.

\section{Discussion}

In patients with recurrent or advanced NSCLC who relapsed following previous platinum-based chemotherapy or EGFR-TKI treatment, docetaxel monotherapy is considered to be the current standard treatment $(5,7)$. During a previous phase III study, in which docetaxel was administered to NSCLC patients who had previously been treated with platinum-based chemotherapy, the time to progression and MST following docetaxel monotherapy was 2.4 and 7.0 months, respectively (6). In the current retrospective study, the median PFS and MST following nab-paclitaxel plus carboplatin treatment were 4.0 and 14.0 months, respectively. These results reveal that nab-paclitaxel plus carboplatin treatment, administered as a second or later-line chemotherapy, may be a promising therapeutic approach; however, careful consideration is required, as the present study was retrospective with a small sample size. In addition, the dose setting for each agent varied as the condition of the patients depended on their previous treatments and disease status.

The use of nab-paclitaxel in combination with carboplatin in chemotherapy-naïve patients with stage III/IV NSCLC has exhibited a promising efficacy (16). A previous phase III trial revealed that the ORR of nab-paclitaxel with carboplatin was significantly higher, compared with that obtained following traditional solvent-based paclitaxel treatment, and that the PFS and OS were similar in the two groups (PFS, 6.3 vs. 5.8 months; and $\mathrm{OS}, 12.1$ vs. 11.2 months; $\mathrm{P}=0.214$ and $\mathrm{P}=0.271$, respectively) $(16)$.

In the present study, 11/25 (44\%) patients had squamous cell carcinoma. The prognosis of squamous cell carcinoma is poor, as compared with that of other non-squamous subtypes (27). The treatment options for patients with squamous cell carcinoma are also currently limited (National Comprehensive Cancer Network guidelines) (28), and EGFR mutations and ALK rearrangements, which are targetable by TKIs, are rare (29). In addition, bevacizumab and pemetrexed are not indicated for use in these patients $(2,30)$. A subset analysis of previous phase III trials (14), based on predefined stratification factors, revealed that patients with squamous histology treated with nab-paclitaxel in combination with carboplatin had a significantly higher ORR, compared with those patients who received solvent-based paclitaxel plus carboplatin (41 vs. $24 \%$; $\mathrm{P}<0.001$ ). In the current study, the ORR and DCR of the patients with squamous cell carcinoma treated with nab-paclitaxel plus carboplatin were observed to be 36.4 and $81.8 \%$, respectively. These results demonstrate a higher efficacy, compared with that of traditional solvent-based paclitaxel, and may be useful as a second-phase or later chemotherapy for the treatment of squamous cell carcinoma.

In the present study, the most common adverse effects observed during nab-paclitaxel treatment were myelosuppression, sensory neuropathy, gastrointestinal reactions and 
Table IV. Response rates following nanoparticle albumin-bound-paclitaxel plus carboplatin treatment.

\begin{tabular}{|c|c|c|c|c|c|c|c|c|c|}
\hline Clinical factor & Number of patients & CR & PR & $\mathrm{SD}$ & $\mathrm{PD}$ & ORR, $\%$ & P-value & DCR, \% & P-value \\
\hline \multicolumn{10}{|l|}{ Gender } \\
\hline Male & 19 & 1 & 6 & 7 & 5 & 36.8 & \multirow[t]{2}{*}{0.356} & 73.7 & \multirow[t]{2}{*}{0.739} \\
\hline Female & 6 & 0 & 1 & 3 & 2 & 16.7 & & 66.7 & \\
\hline \multicolumn{10}{|l|}{ Age, years } \\
\hline$<70$ & 18 & 0 & 3 & 10 & 5 & 16.7 & \multirow[t]{2}{*}{$0.008^{\mathrm{a}}$} & 72.2 & \multirow[t]{2}{*}{0.968} \\
\hline$\geq 70$ & 7 & 1 & 4 & 0 & 2 & 71.4 & & 71.4 & \\
\hline \multicolumn{10}{|l|}{ Histology } \\
\hline $\mathrm{Sq}$ & 11 & 0 & 4 & 5 & 2 & 36.4 & \multirow[t]{2}{*}{0.678} & 81.8 & \multirow[t]{2}{*}{0.332} \\
\hline Non-Sq & 14 & 1 & 3 & 5 & 5 & 28.6 & & 64.3 & \\
\hline \multicolumn{10}{|l|}{ Phase } \\
\hline 2nd line & 13 & 0 & 6 & 4 & 3 & 46.2 & \multirow[t]{2}{*}{0.114} & 76.9 & \multirow[t]{2}{*}{0.568} \\
\hline 3rd line or later & 12 & 1 & 1 & 6 & 4 & 16.7 & & 66.7 & \\
\hline Total & 25 & 1 & 7 & 10 & 7 & 32.0 & N.A. & 72.0 & N.A. \\
\hline
\end{tabular}

${ }^{a} \mathrm{P}<0.05$ indicates a statistically significant difference. $\mathrm{CR}$, complete response; $\mathrm{PR}$, partial response; $\mathrm{SD}$, stable disease; $\mathrm{PD}$, progressive disease; ORR, overall response rate; DCR, disease control rate; Sq, squamous cell carcinoma; N.A., not applicable.

Table V. Grade of adverse events following treatment with nanoparticle albumin-bound-paclitaxel plus carboplatin.

\begin{tabular}{llll}
\hline & \multicolumn{3}{c}{ CTCAE grade } \\
\cline { 2 - 4 } Adverse events & I/II (\%) & III (\%) & IV (\%) \\
\hline Leukopenia & $5(20)$ & $6(24)$ & $1(4)$ \\
Thrombocytopenia & $4(16)$ & $3(12)$ & $0(0)$ \\
Anemia & $0(0)$ & $2(8)$ & $0(0)$ \\
Neurotoxicity & $7(28)$ & $0(0)$ & $0(0)$ \\
Gastrointestinal symptoms & $5(20)$ & $1(4)$ & $0(0)$ \\
Baldness & $3(12)$ & $0(0)$ & $0(0)$ \\
Edema & $1(4)$ & $0(0)$ & $0(0)$ \\
Vertigo & $1(4)$ & $0(0)$ & $0(0)$ \\
\hline
\end{tabular}

CTCAE, common terminology criteria for adverse events.

alopecia. The majority of patients experienced grade 1 or 2 adverse events and there were no treatment-associated mortalities during or following treatment with nab-paclitaxel. In a previous phase III trial, grade $\geq 3$ neutropenia, thrombocytopenia, anemia and sensory neuropathy were reported at a rate of $41,18,27$ and $3 \%$, respectively, in the nab-paclitaxel with carboplatin treatment group (16). The present study observed rates of $28,12,8$ and $0 \%$, respectively, which were comparable with the prospective data, despite the inclusion of patients who had undergone previous chemotherapy that may have adversely affected their physical condition. Therefore, nab-paclitaxel in combination with platinum appears to be an optimal late-phase treatment option, due to its efficacy and favorable safety profile.
The number of elderly patients diagnosed with lung cancer has increased worldwide $(31,32)$. Comorbid diseases and adverse medical conditions, including chronic lung disease, insufficient cardiac function, renal impairment and other age-associated conditions, have become major concerns in the treatment of elderly NSCLC patients, who occasionally experience difficulties in undergoing cytotoxic chemotherapy (33). Therefore, regimens that may be used to treat elderly patients with comorbidities are restricted. In the current study, the ORR of patients aged $\geq 70$ years were superior to that of patients aged $<70$ years, and the DCR of patients aged $\geq 70$ years were similar to that of patients aged $<70$ years. In addition, the adverse events observed in patients aged $\geq 70$ years were similar to those observed in patients aged $<70$ years. These findings demonstrate that this regimen may also be promising for use in elderly patients with NSCLC.

In the present study, the previous chemotherapy regimens administered prior to nab-paclitaxel primarily consisted of platinum-doublets or EGFR-TKI (Table II). In addition, later chemotherapy regimens, which were administered following nab-paclitaxel plus carboplatin treatment, included docetaxel monotherapy, EGFR-TKI, S-1 monotherapy, radiation therapy and best supportive care. In later chemotherapy phases, platinum-doublet chemotherapy is rarely selected, as the physical condition of patients who require later-phase chemotherapy is typically poor. Two retrospective studies evaluated the efficacy of nab-paclitaxel monotherapy following previous chemotherapy, and reported that the ORR was 30.0 (34) and 28.6\% (35), and the median PFS was 5.0 (34) and 4.0 months (35), respectively. In the current study, the median PFS was 4.0 months, which was comparable to the PFS reported in previous studies; the PFS was also high, as compared with the PFS obtained using docetaxel monotherapy as a second-line chemotherapy. 

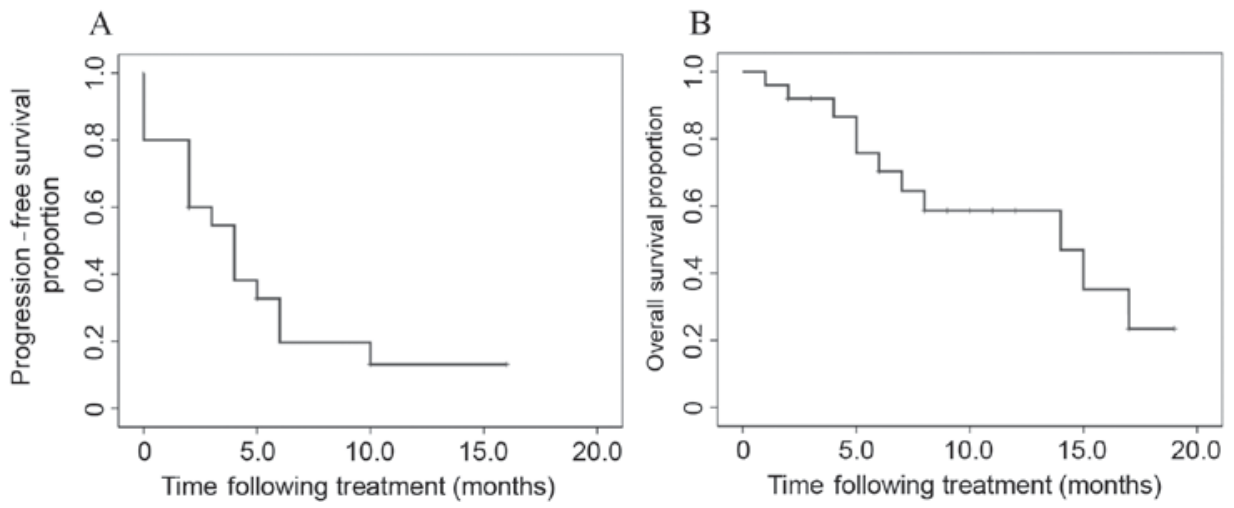

Figure 1. The median (A) progression-free survival time and (B) overall survival time following nab-paclitaxel plus carboplatin treatment were 4.0 and 14.0 months, respectively.
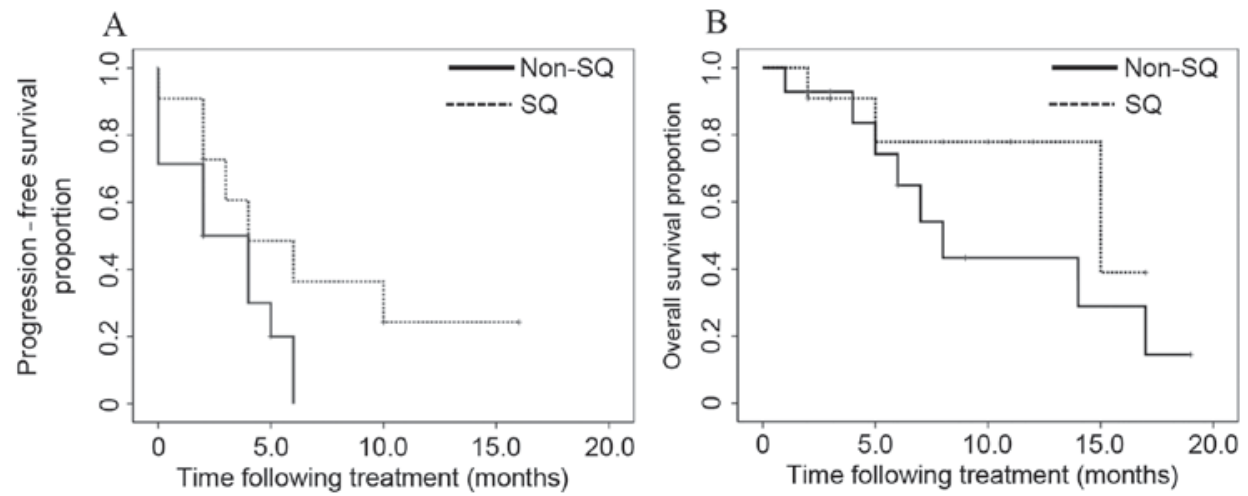

Figure 2. In the subgroups divided according to histology (SQ vs. non-SQ cell carcinoma), (A) the median progression-free survival time and (B) the overall survival time were not significantly different between the two groups ( $\mathrm{P}=0.110$ and $\mathrm{P}=0.245$, respectively). $\mathrm{SQ}$, squamous.
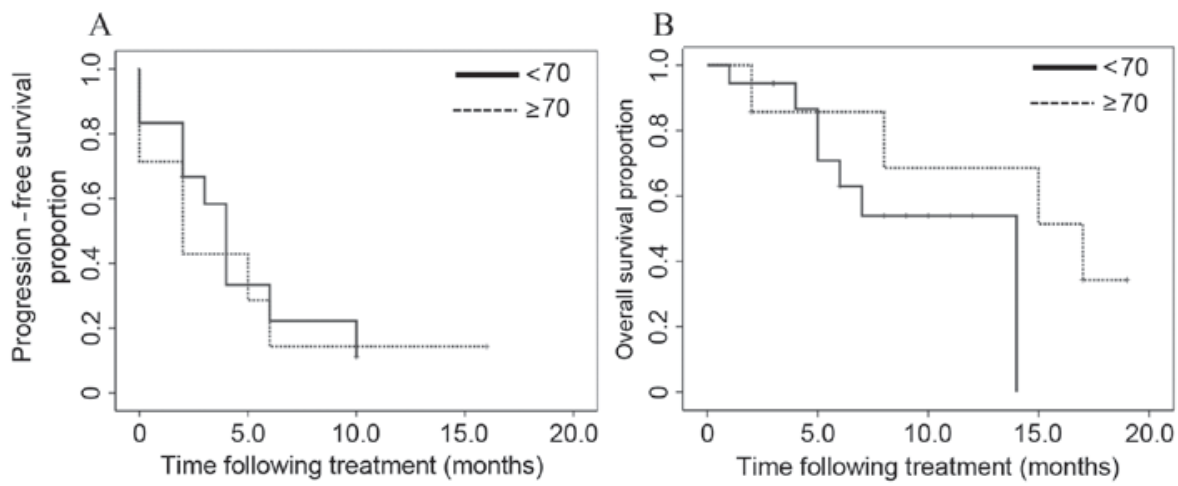

Figure 3. In the subgroups divided according to age ( $<70$ vs. $\geq 70$ years), (A) the median progression-free survival time and (B) the overall survival time following treatment were not significantly different between the two groups $(\mathrm{P}=0.727$ and $\mathrm{P}=0.270$, respectively).

To the best of our knowledge, the results of the present study are the first to demonstrate that nab-paclitaxel plus carboplatin is a promising and tolerable late-phase chemotherapy for NSCLC. However, the current study had two limitations. Firstly, only a small sample size of 25 patients was evaluated, and, secondly, there was a risk of selection bias due to the retrospective nature of the study. In conclusion, nab-paclitaxel plus carboplatin administered as a second-phase or later-phase chemotherapy offers a small but significant survival benefit for patients with recurrent and advanced-stage IIIB/IV NSCLC, with tolerable adverse effects. However, further prospective studies of this regimen as a late-phase chemotherapeutic agent are required.

\section{References}

1. Surveillance, epidemiology and end results (SEER) cancer statistics review, 1975-2010,2013.http://seer.cancer.gov/csr/1975_2010. Accessed 14 June, 2013.

2. Scagliotti GV, Parikh P, von Pawel J, Biesma B, Vansteenkiste J, Manegold C, Serwatowski P, Gatzemeier U, Digumarti R, Zukin M, et al: Phase III study comparing cisplatin plus gemcitabine with cisplatin plus pemetrexed in chemotherapy-naïve patients with advanced-stage non small cell lung cancer. J Clin Oncol 26: 3543-3551, 2008

3. Mok TS, Wu Y, Thongprasert S, Yang $\mathrm{CH}$, Chu DT, Saijo N, Sunpaweravong P, Han B, Margono B, Ichinose Y, et al: Gefitinib or carboplatin-paclitaxel in pulmonary adenocarcinoma. N Eng J Med 361: 947-957, 2009. 
4. Ciuleanu T, Brodowicz T, Zielinski C, Kim JH, Krzakowski M, Laack E, Wu YL, Bover I, Begbie S, Tzekova V, et al: Maintenance pemetrexed plus best supportive care versus placebo plus best supportive care for non-small cell lung cancer: A randomized, double-blind, phase 3 study. Lancet 374: 1432-1440, 2009.

5. Fossella FV, DeVore R, Kerr RN, Crawford J, Natale RR, Dunphy F, Kalman L, Miller V, Lee JS, Moore M, et al: Randomized phase III trial of docetaxel versus vinorelbine or ifosfamide in patients with advanced non-small cell lung cancer previously treated with platinum-containing chemotherapy regimens. The TAX 320 Non-Small Cell Lung Cancer Study Group. J Clin Oncol 18: 2354-2362, 2000

6. Shepherd FA, Dancey J, Pamlau R, Mattson K, Gralla R, O'Rourke M, Levitan N, Gressot L, Vincent M, Burkes R, et al: Prospective randomized trial of docetaxel versus best supportive care in patients with non-small cell lung cancer previously treated with platinum-based chemotherapy. J Clin Oncol 18: 2095-2103, 2000.

7. Shepherd FA, Rodrigues Pereira J, Ciuleanu T, Tan EH, Hirsh V, Thongprasert S, Campos D, Maoleekoonpiroj S, Smylie M, Martins R, et al: Erlotinib in previously treated non-small cell lung cancer. N Eng J Med 353: 123-132, 2005.

8. Hanna N, Shepherd FA, Fossella FV, Pereira JR, De Marinis F, von Pawel J, Gatzemeier U, Tsao TC, Pless M, Muller T, et al: Randomized phase III trial of pemetrexed versus docetaxel in patients with non-small cell lung cancer previously treated with chemotherapy. J Clin Oncol 22: 1589-1597, 2004.

9. Shaw AT, Kim DW, Nakagawa K, Seto T, Crinó L, Ahn MJ, De Pas T, Besse B, Solomon BJ, Blackhall F, et al: Crizotinib versus chemotherapy in advanced ALK-positive lung cancer. N Eng J Med 368: 2385-2394, 2013.

10. Baggstrom MQ, Stinchcombe TE, Fried DB, Poole C, Hensing TA and Socinski MA: Third-generation chemotherapy agents in the treatment of advanced non-small cell lung cancer. A meta-analysis. J Thorac Oncol 2: 845-853, 2007.

11. Fang Y, Wang L, Xia GH and Shi MQ: Clinical investigation of efficacy of albumin bound paclitaxel plus platinum compounds as first-line chemotherapy for stage III/IV squamous non-small cell lung cancer. Asian Pac J Cancer Prev 15: 7453-7457, 2014.

12. Kelly K, Crowley J, Bunn PA Jr, Presant CA, Grevstad PK, Moinpour CM, Ramsey SD, Wozniak AJ, Weiss GR Moore DF, et al: Randomized phase III trial of paclitaxe plus carboplatin versus sinorelbine plus cisplatin in the treatment of patients with advanced non-small cell lung cancer: A Southwest Oncology Group trial. J Clin Oncol 19: 3210-3218, 2001.

13. John TA, Vogel SM, Tiruppathi C, Malik AB and Minshall RD: Quantitative analysis of albumin uptake and transport in the rat microvessel endothelial monolayer. Am J Physiol Lung Cell Mol Physiol 284: L187-L196, 2003.

14. Schnitzer JE and Oh P: Albondin-mediated capillary permeability to albumin. Differential role of receptors in endothelial transcytosis and endocytosis of native and modified albumins. J Biol Chem 269: 6072-6082, 1994.

15. Matsumura Y and Maeda H: A new concept for macromolecular therapeutics in cancer chemotherapy: Mechanism of tumoritropic accumulation of proteins and the antitumor agent smancs. Cancer Res 46: 6387-6392, 1986.

16. Socinski MA, Bondarenko I, Karaseva NA, Makhson AM, Vynnychenko I, Okamoto I, Hon JK, Hirsh V, Bhar P, Zhang $\mathrm{H}$, et al: Weekly nab-paclitaxel in combination with carboplatin versus solvent-based paclitaxel plus carboplatin as first-line therapy in patients with advanced non-small cell lung cancer: Final results of a phase III trial. J Clin Oncol 30: 2055-2062, 2012.

17. Yang JJ, Huang C, Chen GY, Song Y, Cheng Y, Yan HH, Zhou Q and Wu YL: A randomized phase II clinical trial of nab-paclitaxe and carboplatin compared with gemcitabine and carboplatin as first-line therapy in locally advanced or metastatic squamous cell carcinoma of lung. BMC Cancer 14: 684, 2014

18. Langer CJ, Hirsh V, Ko A, Renschler MF and Socinski MA Weekly nab-paclitaxel in combination with carboplatin as first-line therapy in patients with advanced non-small cell lung cancer: Analysis of safety and efficacy in patients with renal impairment. Clin Lung Cancer 16: 112-120, 2015.

19. Chen H, Huang X, Wang S, Zhen X, Lin J, Li P and Lin L: Nab-paclitaxel (abraxane)-based chemotherapy to treat elderly patients with advanced non-small cell lung cancer: A single center, randomized and open-label clinical trial. Chin J Cancer Res 27: 190-196, 2015.
20. Ishihara M, Igawa S, Maki S, Harada S, Kusuhara S, Niwa H, Otani S, Sasaki J, Jiang SX and Masuda N: Successful chemotherapy with nab-paclitaxel in a heavily treated non-small cell lung cancer patient: A case report. Case Rep Oncol 7: 401-406, 2014.

21. Goldstraw P, Crowley J, Chansky K, Giroux DJ, Groome PA, Rami-Porta R, Postmus PE, Rusch V and Sobin L; International Association for the Study of Lung Cancer International Staging Committee; Participating Institutions: The IASLC Lung Cancer Staging Project: Proposals for the revision of the TNM stage groupings in the forthcoming (seventh) edition of the TNM Classification of malignant tumours. J Thorac Oncol 2: 706-714, 2007.

22. Travis WD, Brambilla E, Burke AP, Marx A and Nicholson AG: Introduction to The 2015 World Health Organization Classification of Tumors of the Lung, Pleura, Thymus, and Heart. J Thorac Oncol 10: 1240-1242, 2015.

23. Oken MM, Creech RH, Tormey DC, Horton J, Davis TE, McFadden ET and Carbone PP: Toxicity and response criteria of the Eastern Cooperative Oncology Group. Am J Clin Oncol 5: 649-655, 1982

24. Conklin CM, Craddock KJ, Have C, Laskin J, Couture C and Ionescu DN: Innmunohistochemistry is a reliable screening tool for identification of ALK rearrangement in non-small cell lung carcinoma and is antibody dependent. J Thorac Oncol 8: 45-51, 2013.

25. Therasse P, Arbuck SG, Eisenhauer EA, Wanders J, Kaplan RS, Rubinstein L, Verweij J, Van Glabbeke M, van Oosterom AT, Christian MC and Gwyther SG: New guidelines to evaluate the response to treatment in solid tumors. European organization for research and treatment of cancer, National cancer institute of the United states, National cancer institute of Canada. J Natl Cancer Inst 92: 205-216, 2000.

26. NationalCancer Institute: Cancer Therapy Evaluation Program. Common Terminology Criteria for Adverse Events. Version 4.0 http://ctep/.cancer.gov/protocolDevelopment/electronic_applications/ctc.htm. Accessed August 2, 2012.

27. Kawase A, Yoshida J, Ishii G, Nakao M, Aokage K, Hishida T, Nishimura M and Nagai K: Differences between squamous cell carcinoma and adenocarcinoma of the lung: Are adenocarcinoma and squamous cell carcinoma prognostically equal? Jpn J Clin Oncol 42: 189-195, 2012.

28. https://www.nccn.org/professionals/physician_gls/pdf/nscl.pdf. Accessed January 17, 2013.

29. Lindeman NI, Cagle PT, Beasley MB, Chitale DA, Dacic S, Giaccone G, Jenkins RB, Kwiatkowski DJ, Saldivar JS, Squire J, et al: Molecular testing guideline for selection of lung cancer patients for EGFR and ALK tyrosine kinase inhibitors: Guideline from the college of American pathologists, international association for the study of lung cancer, and association for molecular pathology. J Thorac Oncol 8: 823-859, 2013.

30. Sandler AB, Schiller JH, Gray R, Dimery I, Brahmer J, Samant M, Wang LI and Johnson DH: Retrospective evaluation of the clinical and radiographic risk factors associated with severe pulmonary hemorrhage in first-line advanced, unresectable non-small-cell lung cancer treated with carboplatin and paclitaxel plus bevacizumab. J Clin Oncol 27: 1405-1412, 2009.

31. Matsuda A, Matsuda T, Shibata A, Katanoda K, Sobue T and Nishimoto H; Japan Cancer Surveillance Research Group: Cancer incidence and incidence rates in Japan in 2008: A study of 25 population-based cancer registries for the Monitoring of Cancer Incidence in Japan (MCIJ) project. Jpn J Clin Oncol 44: 388-396, 2013

32. Katanoda K, Hori M, Matsuda T, Shibata A, Nishino Y, Hattori M, Soda M, Ioka A, Sobue T and Nishimoto H: An updated report on the trends in cancer incidence and mortality in Japan, 1958-2013. Jpn J Clin Oncol 45: 390-401, 2015.

33. Oshita F, Kurata T, Kasai T, Fukuda M, Yamamoto N, Ohe Y, Tamura T, Eguchi K, Shinkai T and Saijo N: Prospective evaluation of the feasibility of cisplatin-based chemotherapy for elderly lung cancer patients with normal organ functions. Jpn J Cancer Res 86: 1198-1202, 1995.

34. Zheng Q, Yao Y and Nan K: Weekly intravenous nanoparticle albumin-bound paclitaxel for elderly patients with stage IV non-small cell lung cancer: A series of 20 cases. J Biomed Res 26: 159-164, 2012.

35. Xing PY, Li JL, Wang Y, Hao XZ, Wang B, Yang L, Shi YK and Zhang XR: Efficacy and safety of albumin-bound paclitaxel in treating recurrent advanced non-small cell lung cancer. Chin J Cancer Res 25: 200-205, 2013 